\title{
Pengembangan Program Linear Multi-Objektif Fuzzy Stokastik Model Simetris dan Penyelesaiannya dengan Menggunakan Teknik Chance Constrained
}

\author{
Ernestina Lalian ${ }^{1}$, Grandianus Seda Mada ${ }^{2 *}$, Faustianus Luan $^{3}$, Eva Binsasi $^{4}$ \\ 1,2,3,4 Program Studi Matematika, Fakultas Pertanian, Universitas Timor, Kefamenanu, TTU - NTT, Indonesia. \\ *Email korespondensi: grandianusmada@gmail.com
}

\section{Article Info}

\section{Article history:}

Received: 17 November 2021

Received in revised form: 01 Desember 2021

Accepted : 15 Desember 2021

\section{Doi: https://doi.org/10.32938/slk.v4i2.1535}

\section{Keywords:}

Model Simetris,

PLMOFS - PLSOD,

Teknik Chance Constrained

\begin{abstract}
Abstrak
Program linear merupakan salah satu metode penentuan nilai optimum dari suatu persoalan. Persoalan-persoalan program linear yang dihadapi para pengambil keputusan mengalami berbagai variasi dari waktu ke waktu. Berbagai masalah yang ada dapat dipandang sebagai program linear multi-objektif fuzzy, program linear muli-objektif stokastik, ataupun kombinasi keduanya. Penelitian ini berfokus pada Program Linear Multi-Objektif Fuzzy Stokastik (PLMOFS) dengan setiap fungsi tujuan memiliki tingkat kepentingan yang sama bagi pengambil keputusan atau disebut dengan model simetris. Fungsi tujuan dari PLMOFS ini mengandung parameter fuzzy dan variabel random berdistribusi normal sedangkan fungsi kendalanya mengandung parameter fuzzy. Tujuan dari penelitian ini yaitu memformulasikan PLMOFS dan menyusun algoritma untuk mentransformasi PLMOFS menjadi Program Linear Single-Objektif Deterministik (PLSOD) yang kemudian dapat diselesaikan menggunakan metode simpleks. Dalam mentransformasi PLMOFS menjadi PLSOD digunakan teknik chance constrained. Pada akhirnya diberikan contoh numerik untuk mengilustrasikan cara penyelesaian dari algoritma yang telah disusun. Model dan algoritma yang telah dibentuk diharapkan dapat membantu pengambil keputusan dalam menyelesaikan berbagai persoalan.
\end{abstract}

\section{Pendahuluan}

Berbagai masalah dalam proses pengambilan keputusan bersifat multidimensi dan memiliki berbagai tujuan sehingga lebih diperlukan pendekatan multi-objektif dari pada pendekatan single objektif (Sakawa, 1993). Namun mengingat ketidaktepatan atau ketidakjelasan yang melekat dalam penilaian manusia, dan penilaiannya perlu dimasukkan ke dalam masalah pengoptimalan multi-objektif maka Zimmerman (1978) dalam Sakawa (1993) menggunakan teori himpunan fuzzy ke dalam program linear multi-objektif yang kemudian disebut sebagai program linear multi-objektif fuzzy.

Amid dkk (2006) menjelaskan bahwa Belman dan Zadeh mengembangkan sebuah model untuk memecahkan program linear multiobjektif fuzzy. Dalam modelnya tujuan dan kendala memiliki tingkat kepentingan yang sama sehingga model ini disebut model simetris. Namun model simetris yang dikemukan oleh Amid dkk (2006) hanya sampai pada tujuannya yang bersifat fuzzy sedangkan kendalanya masih deterministik.

Cheng dkk (2013) mengembangkan program linear multi-objektif dengan fungsi objektif fuzzy dan kendala fuzzy serta menyelesaikannya dengan menggunakan metode standar devisiasi kemudian Mada (2019.) mengembangkan program linear multi-objektif dengan fungsi objektif fuzzy dan kendala fuzzy yang dikembangkan oleh Cheng dkk (2013) dan menyelesaikan dengan menggunakan model simetris yang dikemukan oleh Amid dkk (2006). Selanutnya, Hulsurkar dkk (1997) mengembangkan model program linear multiobjektif fuzzy stokastik dan menyelesaikan dengan menggunakan teknik chance constrained. Penelitian ini fokus mengembangkan model Program Linear Multiobjektif Fuzzy Stokastik dengan mengkombinasikan model yang dikenalkan oleh Hulsurkar dkk (1997) dan model yang dikembangkan oleh Mada (2019) serta menyelesaikannya dengan menggunakan model simetris yang dikembangkan oleh Amid dkk (2006) dan Mada (2019) serta teknik chance constrained yang dikembangkan oleh Hulsurkar dkk (1997).

\section{Metode}

Penelitian ini merupakan penelitian kajian eksplorasi dengan mengkaji beberapa jurnal, buku, dan sumber lainnya dari internet. Jurnal utama yang dikaji adalah jurnal Mada (2019) dan jurnal Hulsurkar dkk (1997). Model yang diteliti merupakan model simetris yaitu model dengan setiap fungsi tujuan memiliki tingkat kepentingan yang sama bagi pengambil keputusan. Model yang dikembangkan juga hanya terbatas pada fungsi tujuannya saja yang mengandung variabel random sehingga untuk penelitian lanjutan dapat dikembangkan untuk model dengan fungsi kendalanya saja yang mengandung variabel random ataupun keduanya baik fungsi tujuan maupun fungsi kendala, mengandung variabel random. Dalam menyelesaikan PLMOFS diperlukan transformasi ke bentuk PLSOD. Proses transformasi dilakukan dengan memakai teknik chance constrained yang disampaikan oleh Hulsurkar dkk (1997). dan konsep infimum - supremum fuzzy dari bilangan fuzzy segitiga yang disampaikan oleh Ramík dan Rimanek (1985) dan dikembangkan oleh Nehi dan Alineghad (2008).

\section{Hasil dan Pembahasan}

3.1 Formulasi Program Linear Multi-Objektif Fuzzy Stokastik (PLMOFS)

Model PLMOFS yang merupakan kombinasi dari Mada (2019) dan Hulsurkar dkk (1997) disajikan seperti berikut:

menentukan $\mathbf{x}=\left[x_{1}, x_{2}, \cdots, x_{n}\right]^{T}$ yang

meminimalkan $\tilde{Z}_{k}=\sum_{i=1}^{n} c_{k i} x_{i} \underset{\widetilde{S}}{\widetilde{\leq}} z_{k}^{0}, k=1,2, \cdots, p$,

memaksimalkan $\tilde{Z}_{i}=\sum_{i=1}^{n} c_{l i} x_{i} \underset{\leq}{\leq} z_{l}^{0}, l=p+1, p+2, \cdots, q$,

$g_{p}(x)=\sum_{i=1}^{n} a_{p i} x_{i} \leq b_{p}, p=1,2, \cdots, m$

$x_{i} \geq 0, i=1,2, \cdots, n$

dengan $c_{k i}, c_{l i}$ merupakan variabel random berdistribusi normal, $a_{p}$ dan $b_{p}$ bernilai crisp, $\tilde{a}_{r i}=\left(a_{r i}{ }^{(1)}, a_{r i}{ }^{(2)}, a_{r i}{ }^{(3)}\right)$ dan $\tilde{b}_{r i}=\left(b_{r}{ }^{(1)}, b_{r}{ }^{(2)}, b_{r i}{ }^{(3)}\right)$ adalah parameter fuzzy dari kendala ke-r, $z_{k}^{0}$ dan $z_{l}^{0}$ adalah tingkat aspirasi atau tujuan yang ingin dicapai oleh pembuat keputusan dan tanda tilde $\sim$ menyatakan lingkungan yang bersifat fuzzy.

Program linear (1) belum dapat diselesaikan dengan metode simpleks oleh karena itu perlu dilakukan transformasi ke model PLSOD. Transformasi yang dimaksud terbagi menjadi tiga tahap dengan tahap pertama yaitu mentransformasi variabel random menjadi variabel crisp, tahap kedua yaitu mentransformasi multi-objektif menjadi single-objektif dan tahap ketiga yaitu mentransformasi kendala fuzzy menjadi kendala deterministik.

\subsection{Transformasi Variabel Random menjadi Variabel Crisp}

Karena $c_{k i}$ dan $c_{l i}$ merupakan variabel random berdistribusi normal maka berdasarkan tenik Chance Constrained yang disampaikan oleh Hulsurkar dkk (1997), fungsi objektifnya yaitu $\widetilde{z_{k}}$ dan $\widetilde{z_{l}}$ juga merupakan variabel random berdistribusi normal sehingga mean dari fungsi-fungsi objektifnya adalah: $E\left(\widetilde{z_{k}}\right)=\sum_{i=1}^{n} E\left(c_{k i}\right) x_{i}$

$$
E\left(\widetilde{z_{l}}\right)=\sum_{i=1}^{n} E\left(c_{l i}\right) x_{i}
$$

Dari sini, Program linear (1) dapat berubah menjadi masalah:

Menentukan $\boldsymbol{x}=\left[\begin{array}{llll}x_{1} & x_{2} & \ldots & x_{n}\end{array}\right]^{T}$ yang

Meminimalkan $E\left(\widetilde{z_{k}}\right)=\sum_{i=1}^{n} E\left(c_{k i}\right) x_{i} \widetilde{\leq} z_{k}^{0} \quad k=1,2, \ldots, p$ memaksimalkan $E\left(\widetilde{z_{l}}\right)=\sum_{i=1}^{n} E\left(c_{l i}\right) x_{i} \simeq z_{l}^{0} l=p+1, p+2, \ldots, q$ dengan kendala

$$
\begin{gathered}
\widetilde{g_{r}}(x)=\sum_{i=1}^{n} \widetilde{a_{r l}} x_{i} \widetilde{\leq} \widetilde{b_{r}}, r=1,2, \ldots, h, \\
g_{p}(x)=\sum_{i=1}^{n} a_{p i} x_{i} \leq b_{p}, \quad p=h+1, h+2, \ldots, m, \\
x_{i} \geq 0, i=1,2, \ldots, n .
\end{gathered}
$$

Variabel random pada program linear (4) telah berubah menjadi variabel crisp sehingga program linear (4) disebut sebagai Program Linear Multi-Objektif Fuzzy. Fungsi keanggotaan untuk masing-masing fungsi objektif fuzzy dan kendala fuzzy merupakan fungsi linear sebagai berikut:

$$
\begin{gathered}
\mu_{E\left(Z_{k}\right)}(x)=\left\{\begin{array}{ccc}
1 & ; & Z_{k}(x) \leq Z_{k}^{-} \\
f_{Z_{k}}=\frac{Z_{k}^{+}-Z_{k}(x)}{Z_{k}^{+}-Z_{k}^{-}} & ; & Z_{k}^{-} \leq Z_{k}(x) \leq Z_{k}^{+},(k=1,2, \cdots, p) \\
0 & ; & Z_{k}(x) \geq Z_{k}^{-}
\end{array}\right. \\
\mu_{E\left(Z_{l}\right)}(x)=\left\{\begin{array}{ccc}
1 & Z_{l}(x) \geq Z_{l}^{+} \\
f_{Z_{l}}=\frac{Z_{l}^{+}-Z_{l}^{-}}{Z_{l}^{+}-Z_{l}^{-}} & ; & Z_{l}^{-} \leq Z_{l}(x) \leq Z_{l}^{+},(l=p+1, p+2, \cdots, q) \\
0 \quad & ; & Z_{l}(x) \leq Z_{l}^{-}
\end{array}\right.
\end{gathered}
$$
dengan kendala

$\tilde{g}_{r}(x)=\sum_{i=1}^{n} \tilde{a}_{r i} x_{i} \widetilde{\leq} \tilde{b}_{r}, r=1,2, \cdots, h$ 


$$
\begin{aligned}
& \mu_{a_{r}}(x)=\left\{\begin{array}{lll}
0 & ; & x<a^{(1)}, x>a^{(3)} \\
1-\frac{a^{(2)}-x}{\beta} & ; & a^{(2)}-\beta \leq x \leq a^{(2)} \\
1-\frac{x-a^{(2)}}{\gamma} & ; & a^{(2)} \leq x \leq a^{(2)}+\gamma \\
1 & ; & x=a^{(2)}
\end{array}\right. \\
& \mu_{b_{r}}(x)=\left\{\begin{array}{lll}
0 & ; & x<b^{(1)}, x>b^{(3)} \\
1-\frac{b^{(2)}-x}{\beta} & ; & b^{(2)}-\beta \leq x \leq b^{(2)} \\
1-\frac{x-b^{(2)}}{\gamma} & ; & b^{(2)} \leq x \leq b^{(2)}+\gamma \\
1 & ; & x=b^{(2)}
\end{array}\right.
\end{aligned}
$$

Fungsi keanggotaan untuk fungsi kendala menggunakan definisi bilangan fuzzy segitiga yang disampaikan oleh Kalaichelvi dan Janofer (2012). Grafik fungsi keanggotan (5), (6), (7) dan (8) disajikan pada Gambar 1.

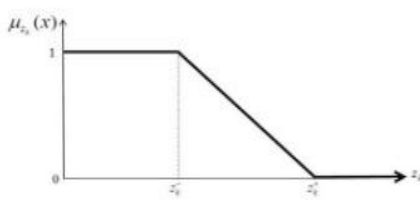

(a)

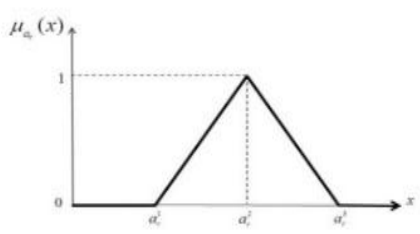

(c)

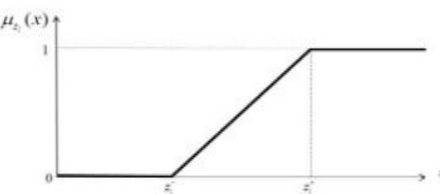

(b)

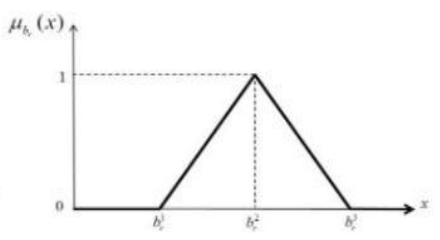

(d)
Gambar 1. Fungsi Keanggotaan dari (a). $Z_{l}(x),(\mathrm{b}) . Z_{k}(x)$, (c). $a_{r}(x)$ dan (d). $b_{r}(x)$

\subsection{Transformasi Multi-Objektif menjadi Single-Objektif}

Berikut diberikan dua definisi yang berperan dalam proses transformasi multi-objektif menjadi single-objektif.

Definisi 3.1 Keputusan fuzzy untuk $q$ fungsi objektif fuzzy dan $h$ kendala fuzzy dengan fungsi objektif fuzzy memiliki kepentingan yang sama didefinisikan oleh fungsi keanggotaan

$$
\begin{aligned}
\mu_{D}(x)=\left\{\bigcap_{j=1}^{q} \mu_{E(z j)}(\boldsymbol{x})\right\} \bigcap\left\{\bigcap_{r=1}^{h} \mu_{g(r)}(\boldsymbol{x})\right\} \\
\Leftrightarrow \mu_{D}(x)=\bigcap_{j=1}^{q} \mu_{E(z j)}(\boldsymbol{x}) \\
\Leftrightarrow \mu_{D}(x)=\min _{j=1,2, \ldots, q} \mu_{E\left(z_{j}\right)}(\boldsymbol{x})
\end{aligned}
$$

Keputusan fuzzy ini disebut Keputusan Fuzzy Simetris.

Definisi 3.2 Keputusan maksimum dari keputusan fuzzy simetris didefinisikan oleh

$\mu_{D}\left(\boldsymbol{x}^{*}\right)=\operatorname{maks}_{\boldsymbol{x} \in X_{d}} \mu_{D}(\boldsymbol{x})$

$$
\begin{aligned}
& \operatorname{maks} \min _{j=1, \ldots, q} \mu_{E\left(z_{j}\right)}(\boldsymbol{x}) \\
& =\operatorname{maks} \min _{x \in X_{d}}\left\{\mu_{E\left(z_{1}\right)}, \mu_{E\left(z_{2}\right)}, \ldots, \mu_{E\left(z_{q}\right)}\right\}
\end{aligned}
$$

Berdasarkan Definisi 3.1 dan 3.2 diatas maka Model Simetris Program Linear (4) dengan fungsi tujuan multi-objektif dapat ditransformasi menjadi single-objektif sebagai berikut:

Menentukan $\boldsymbol{x}=\left[\begin{array}{llll}x_{1} & x_{2} & \ldots & x_{n}\end{array}\right]^{T}$ yang

memaksimalkan $y\left(x_{1}, x_{1}, \ldots, x_{n}, \lambda\right)=\lambda$

dengan kendala

$$
\begin{aligned}
& \lambda \leq \mu_{E\left(z_{j}\right)}(x), j=1,2, \ldots, q \\
& \widetilde{g_{r}}(x)=\sum_{i=1}^{n} \widetilde{a_{r l}} x_{i} \widetilde{b_{r}}, \quad r=1,2, \ldots, h, \\
& g_{p}(x)=\sum_{i=1}^{n} a_{p i} x_{i} \leq b_{p}, \quad p=h+1, h+2, \ldots, m, \\
& x_{i} \geq 0, i=1,2, \ldots, n . \\
& 0 \leq \lambda \leq 1 .
\end{aligned}
$$

Program linear (11) merupakan Program Linear Single-Objektif Fuzzy. Program linear ini belum dapat diselesaikan dengan metode simpleks karena masih mengandung kendala fuzzy.

\subsection{Transformasi Kendala Fuzzy menjadi Kendala Deterministik}

Untuk menyelesaikan program linear fuzzy seperti ini, Balan (2016) serta Nehi dan Alineghad (2008) mengajukan untuk mengubah kendala fuzzy ke bentuk kendala crisp dengan mengubah bentuk bilangan fuzzy segitiga menjadi bentuk bilangan interval sesuai definisi yang diajukan oleh Ramík dan Rimanek (1985)

Bilangan fuzzy $\tilde{A}$ dapat direpresentasikan oleh interval tertutup yang bergantung pada nilai interval dari $\alpha$, atau dapat ditulis sebagai berikut:

$$
\tilde{A}_{\alpha}=\left\{x \mid \mu_{\bar{A}}(x) \geq \alpha\right\}=\left[A_{\alpha}^{L}, A_{\alpha}^{U}\right]
$$

dengan $A_{\alpha}^{L}$ atau $A_{\alpha}^{U}$ masing-masing melambangkan nilai ekstrim kiri atau kanan dari himpunan level- $\alpha, \tilde{A}_{\alpha}$. Khususnya untuk $\tilde{A}=\left(a^{(2)}, \beta, \gamma\right)$ bilangan fuzzy segitiga maka $\tilde{A}=\left[\beta(\alpha-1)+a^{(2)}, a^{(2)}-\gamma(\alpha-1)\right]$ (Nehi \& Alineghad, 2008)

Berikut diberikan Definisi dan Teorema yang menjelaskan tentang transformasi kendala fuzzy ke bentuk kendala deterministik.

Definisi 3.3. (Ramík dan Rimanek, 1985) Diberikan $\widetilde{M}$ dan $\widetilde{N}$ dua bilangan fuzzy, maka

$\widetilde{M} \leq \widetilde{N}$ jika $\widetilde{M} \leq_{L} \widetilde{N}$ dan $\widetilde{M} \leq_{R} \widetilde{N}$

dengan

$\widetilde{M} \leq_{L} \widetilde{N}$ jika inf $\widetilde{M}_{\alpha} \leq_{L}$ inf $\widetilde{N}_{\alpha}$ untuk $\alpha \in[0,1]$ atau ekuivalen dengan kondisi $\forall v \in X \exists u \in X\left[u \leq v \& \mu_{\widetilde{M}}(u) \geq \mu_{\widetilde{N}}(v)\right]$; sedangkan

$\widetilde{M} \leq_{R} \widetilde{N}$ jika sup $\widetilde{M}_{\alpha} \leq_{L}$ sup $\widetilde{N}_{\alpha}$ untuk $\alpha \in[0,1]$ atau ekuivalen dengan kondisi $\forall u \in X \exists v \in X\left[u \leq v \& \mu_{\widetilde{M}}(u) \geq \mu_{\widetilde{N}}(v)\right]$.

Simbol $R$ dan $L$ masing-masing melambangkan relasi sisi kiri dan relasi sisi kanan. Relasi $\widetilde{M} \leq_{R} \widetilde{N}$ menyatakan bahwa $\widetilde{M}$ tidak lebih dari $\widetilde{N}$ dan relasi $\widetilde{M} \leq_{L} \widetilde{N}$ menyatakan bahwa $\widetilde{N}$ tidak kurang dari $\widetilde{M}$ sehingga relasi $\widetilde{M} \leq \widetilde{N}$ menyatakan bahwa $\widetilde{M}$ tidak lebih dari $\widetilde{N}$ atau $\widetilde{N}$ tidak kurang dari $\widetilde{M}$.

Teorema 3.4. (Nehi dan Alineghad, 2008) Diberikan $\widetilde{M}$ dan $\widetilde{N}$ dua bilangan fuzzy, maka

$$
\widetilde{M} \leq \widetilde{N} \Leftrightarrow \widetilde{M} \vee \widetilde{N}=\widetilde{N}
$$

Berdasarkan Definisi 3.1 dan Teorema 3.2, diberikan Teorema berikut. Teorema 3.5. (Nehi dan Alineghad, 2008) Jika $\widetilde{M}$ dan $\widetilde{N}$ dua bilangan fuzzy, $\widetilde{M} \vee \widetilde{N}=\widetilde{N}$ jika dan hanya jika untuk setia $\alpha \in[0,1]$ berlaku $\inf \left\{x: \mu_{\widetilde{N}}(x) \geq \alpha\right\} \geq \inf \left\{x: \mu_{\widetilde{M}}(x) \geq \alpha\right\}$ $\sup \left\{x: \mu_{\widetilde{N}}(x) \geq \alpha\right\} \geq \sup \left\{x: \mu_{\widetilde{M}}(x) \geq \alpha\right\}$

Jika $\widetilde{M}=\left(m^{(2)}, \beta, \gamma\right)$ dan $\widetilde{N}=\left(n^{(2)}, \delta, \tau\right)$ dua bilangan fuzzy, maka diperoleh

$$
\widetilde{M} \leq \widetilde{N} \Leftrightarrow\left\{\begin{array}{c}
m^{(2)} \leq n^{(2)} \\
m^{(2)}-\beta \leq n^{(2)}-\delta \\
m^{(2)}+\gamma \leq n^{(2)}+\tau
\end{array}\right.
$$

dengan $\beta=m^{(2)}-m^{(1)}, \gamma=m^{(3)}-m^{(2)}, \delta=n^{(2)}-n^{(1)}$ dan $\tau=n^{(3)}-$ $n^{(2)}$.

Berdasarkan Teorema 3.5, program linear (10) diubah menjadi:

Menentukan $\mathbf{x}=\left[x_{1}, x_{2}, \cdots, x_{n}\right]^{T}$ yang

memaksimalkan $y\left(x_{1}, x_{1}, \ldots, x_{n}, \lambda\right)=\lambda$ dengan kendala

$$
\begin{aligned}
& \lambda \leq \mu_{E\left(z_{j}\right)}(x), \quad j=1,2, \ldots, q \\
& g_{r}(x)=\sum_{i=1}^{n} a_{r i}^{2} x_{i} \leq b_{r}^{2}, r=1,2, \cdots, h, \\
& g_{r}(x)=\sum_{i=1}^{n}\left(a_{r i}^{2}-\beta\right) x_{i} \leq b_{r}^{2}-\delta, r=1,2, \cdots, h, \\
& \quad g_{r}(x)=\sum_{i=1}^{n}\left(a_{r i}^{2}+\gamma\right) x_{i} \leq b_{r}^{2}+\tau, r=1,2, \cdots, h, \\
& g_{p}(x)=\sum_{i=1}^{n} a_{p i} x_{i} \leq b_{p}, p=h+1, h+2, \cdots, m, \\
& x_{i} \geq 0, i=1,2, \cdots, n
\end{aligned}
$$

dengan $\beta=a_{r i}^{2}-a_{r i}^{1}, \delta=b_{r i}^{2}-b_{r i}^{1}$ masing-masing adalah besar toleransi sisi kiri dari dua parameter fuzzy $\tilde{a}_{r i}$ dan $\tilde{b}_{r}$ sementara $\gamma=a_{r i}^{3}-a_{r i}^{2}, \tau=b_{r i}^{3}-b_{r i}^{2}$ masing-masing adalah besar toleransi sisi kanan dari dua parameter fuzzy $\tilde{a}_{r i}$ dan $\tilde{b}_{r}$.

Program linear (12) merupakan Program Linear Single-Obejktif Deterministik (PLSOD) atau program linear biasa, sehingga dapat diselesaikan dengan metode simpleks. Dengan menyelesaikan (12) diperoleh solusi optimal $\lambda^{*}$ dan $\boldsymbol{x}^{*}$. Solusi optimal $\boldsymbol{x}^{*}$ ini merupakan solusi optimal dari PLMOFS (1) dan $\lambda^{*}$ merupakan derajat keanggotaan untuk $z_{j}\left(\boldsymbol{x}^{*}\right), j=1,2, \ldots, q$. Hal ini dijamin oleh Teorema 3.6 dan Teorema 3.7.

Teorema 3.6 Jika $\boldsymbol{x}^{*} \in X$ adalah solusi optimal tunggal dari PLSOD (12) maka $\boldsymbol{x}^{*}$ adalah solusi optimal pareto dari PLMOFS (1).

Teorema 3.7 Jika $\boldsymbol{x}^{*} \in X$ adalah solusi optimal pareto dari PLMOFS (1), maka $\boldsymbol{x}^{*}$ adalah solusi optimal dari model simetris (12).

\subsection{Algoritma Penyelesesaian Model}

Langkah 1 : Mengkonstruksikan PLMOFS berdasarkan tujuan-tujuan yang dicapai dan kendala-kendala yang dihadapi. 
b. Menentukan minimum dan maksimum individual untuk masing- masing fungsi objektif

c. Mendeskripsikan tujuan fuzzy dan kendala fuzzy

d. Menentukan fungsi keanggotaan untuk fungsi objektif fuzzy dan kendala fuzzy

Langkah 2 : Mentransformasi Variabel Random menjadi Variabel Crisp

Langkah 3 : Mentransformasi Multi-Objektif menjadi Single-Objektif

Langkah 4 : Mentransformasi Kendala Fuzzy menjadi Kendala Deterministik.

Langkah 5 : Menentukan solusi optimal $\boldsymbol{x}^{*}$ dengan menyelesaikan masalah program linear single-objektif deterministik menggunakan metode simpleks.

\subsection{Contoh Numerik}

Diberikan PLMOFS sebagai berikut:

meminimalkan $Z_{1}=c_{11} x_{1}+c_{12} x_{2}+c_{13} x_{3} \widetilde{\simeq} 23745,6$

memaksimalkan $Z_{2}=c_{21} x_{1}+c_{22} x_{2}+c_{23} x_{3} \geq 1289,64$

memaksimalkan $Z_{3}=c_{31} x_{1}+c_{32} x_{2}+c_{33} x_{3} \geq 1260,56$

dengan kendala:

$$
x_{1}+x_{2}+x_{3}=1500
$$

$(0.90,0.91,0.92) x_{1} \underset{\leq}{\widetilde{S}}(515,568,622)$

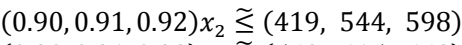

$$
\begin{aligned}
& (0.90,0.91,0.92) x_{3} \widetilde{\leq}(562,615,669) \\
& x_{i} \geq 0, i=1,2,3 \text {. }
\end{aligned}
$$

dengan $Z_{1}$ menyatakan harga, $Z_{2}$ menyatakan tingkat kualitas dan $Z_{3}$ menyatakan tingkat pelayanan. $c_{11}, c_{12}, c_{13}, c_{21}, c_{22}, c_{23}, c_{31}, c_{32}$, dan $c_{33}$ merupakan variabel random berdistribusi normal dengan meannya diperoleh dari Tabel 1.

\section{Tabel 1. Informasi Kuantitatif Supplier}

\begin{tabular}{|c|c|c|c|c|c|c|c|c|c|}
\hline \multirow{2}{*}{ No } & \multicolumn{3}{|c|}{$\begin{array}{c}\text { Harga } \\
\text { (Rp/Kemasan) }\end{array}$} & \multicolumn{3}{c|}{$\begin{array}{c}\text { Kualitas } \\
(\%)\end{array}$} & \multicolumn{3}{c|}{$\begin{array}{c}\text { Pelayanan } \\
(\%)\end{array}$} \\
\cline { 2 - 11 } & $\mathbf{S 1}$ & $\mathbf{S 2}$ & $\mathbf{S 3}$ & $\mathbf{S 1}$ & $\mathbf{S 2}$ & $\mathbf{S 3}$ & S1 & S2 & S3 \\
\hline 1 & 15000 & 15000 & 15500 & 95 & 95 & 95 & 90 & 90 & 90 \\
\hline 2 & 16000 & 15500 & 15500 & 90 & 80 & 85 & 80 & 85 & 90 \\
\hline 3 & 15500 & 16000 & 15000 & 85 & 80 & 80 & 80 & 85 & 80 \\
\hline 4 & 16500 & 15000 & 16500 & 80 & 85 & 85 & 85 & 85 & 80 \\
\hline 5 & 17500 & 16000 & 17000 & 85 & 80 & 85 & 80 & 80 & 80 \\
\hline Jumlah & $\mathbf{8 0 5 0 0}$ & $\mathbf{7 7 5 0 0}$ & $\mathbf{7 9 5 0 0}$ & $\mathbf{4 3 5}$ & $\mathbf{4 2 0}$ & $\mathbf{4 3 0}$ & $\mathbf{4 1 5}$ & $\mathbf{4 2 5}$ & $\mathbf{4 2 0}$ \\
\hline Mean & $\mathbf{1 6 1 0 0}$ & $\mathbf{1 5 5 0 0}$ & $\mathbf{1 5 9 0 0}$ & $\mathbf{8 7}$ & $\mathbf{8 4}$ & $\mathbf{8 6}$ & $\mathbf{8 3}$ & $\mathbf{8 5}$ & $\mathbf{8 4}$ \\
\hline
\end{tabular}

$\mathrm{S} 1=$ Supplier 1, S2= Supplier 2, S3= Supplier 3. menjadi:

Berdasarkan program linear (12), PLMOFS (13) ditransformasi

Tentukan $x_{1}, x_{2}, x_{3}$ yang

Memaksimalkan $\lambda$

Dengan kendala:

$$
\begin{aligned}
\lambda \leq & \frac{23842,8-\left(16.1 x_{1}+15.5 x_{2}+15.9 x_{3}\right)}{97.2} \\
\lambda \leq & \frac{\left(0,87 x_{1}+0,84 x_{2}+0,86 x_{3}\right)-1284,78}{4,86} \\
& \frac{\left(0,83 x_{1}+0,85 x_{2}+0,84 x_{3}\right)-1257,32}{3,24} \\
& x_{1}+x_{2}+x_{3}=1500 \\
& 0,90 x_{1} \leq 515 \\
& 0,91 x_{1} \leq 568 \\
& 0,90 x_{1} \leq 622 \leq 419 \\
& 0,91 x_{2} \leq 544 \\
& 0,92 x_{2} \leq 598 \\
& 0,90 x_{3} \leq 562 \\
& 0,91 x_{3} \leq 615 \\
& 0,92 x_{3} \leq 669 \\
& x_{1}, x_{2}, x_{3} \geq 0 \\
& \lambda \in[0,1] . \\
& 0 p t i n
\end{aligned}
$$

yang menghasilkan solusi optimal sebagai berikut:

$$
x_{1}=453, x_{2}=423 \text {, dan } x_{3}=624
$$

$Z_{1}=11.008, Z_{2}=847,7$, dan $Z_{3}=787,45$

Tingkat pencapaian fungsi objektifnya adalah

$\mu_{Z_{1}}=0, \quad \mu_{Z_{3}}=0.73, \quad \mu_{Z_{2}}=0.26$

\section{Simpulan}

Dalam menyelesaikan Program Linear Multi-Objektif Fuzzy Stokastik (PLMOFS), perlu dilakukan transformasi PLMOFS menjadi Program Linear Single-Objektif Deterministik (PLSOD) sehingga program linear tersebut dapat diselesaikan dengan metode simpleks. Proses transformasi terbagi menjadi tiga tahap dengan tahap pertama yaitu mentransformasi variabel random menjadi variabel crisp, tahap kedua yaitu mentransformasi multi-objektif menjadi single objektif dan tahap ketiga yaitu mentransformasi kendala fuzzy menjadi kendala deterministik

\section{Pustaka}

Amid, A., Ghodsypour, S. H., O’Brien, C. 2006. Fuzzy multiobjective linear model for supplier selection in a supply chain. International Journal of Production Economics, 104(2), 394-407. https://doi.org/10.1016/j.ijpe.2005.04.012

Balan, B. T. 2016. Solving Multi-Objective Fuzzy Linear Optimization Problem Using Fuzzy Programming Technique. IOSR Journal of Mathematics, 4.

Cheng, H., Huang, W., Zhou, Q., Cai, J. 2013. Solving fuzzy multiobjective linear programming problems using deviation degree measures and weighted max-min method. Applied Mathematical Modelling, 37(10-11), 68556869. https://doi.org/10.1016/j.apm.2013.01.048

Hulsurkar, S., Biswal, M. P., Sinha, S. B. 1997. Fuzzy programming approach to multi-objective stochastic linear programming problems. Fuzzy Sets and Systems, 88(2), 173-181. https://doi.org/10.1016/S0165-0114(96)00056-5

Kalaichelvi, D. A., Janofer, K. 2012. $\alpha$-Cuts Of Triangular Fuzzy Numbers And A-Cuts Of Triangular Fuzzy Number Matrices. Int Jr. of Mathematics Sciences \& Applications, 2 (2), 655-645.

Mada, G. S. 2019. Model Pembobotan Aditif Termodifikasi Untuk Menyelesaikan Masalah Pemilihan Supplier Multi-Objektif Fuzzy dengan Fungsi Objektif Fuzzy Dan Kendala Fuzzy Pada Rantai Supply. Prosiding Seminar Nasional Sainstek IV Universitas Nusa Cendana Kupang, 25 Oktober 2019.

Nehi, H. M., Alineghad, M. 2008. Solving Interval and Fuzzy Multi Objective Linear Programming Problem by Necessarily Efficiency Points. 8.

Ramík, J., Rimanek, J. 1985. Inequality relation between fuzzy numbers and its use in fuzzy optimization. Fuzzy Sets and Systems, 16(2), 123 138. https://doi.org/10.1016/S0165-0114(85)80013-0

Sakawa, M. 1993. Fuzzy Sets and Interactive Multiobjective Optimization. Springer US. https://doi.org/10.1007/978-1-4899-1633-4 